\title{
HISTORICIDADE, MUDANÇAS RELAGIONAIS E NÃO FIXIDEZ DO PASSADO EXISTENCIAL ${ }^{12}$
}

\section{Róbson Ramos dos Reis (UFSM) ${ }^{3}$}

robsonramosdosreis@gmail.com

Resumo: No presente artigo, apresento uma interpretação da mobilidade histórica da existência segundo a analítica existencial de Ser e tempo de Martin Heidegger. A interpretação é elaborada com uma construção conceitual que tem por base as noções de mudança relacional e emergência de determinações. Seguindo um análogo do critério de David Weberman para identificar mudanças relacionais genuínas, examinarei a mobilidade específica da historicidade existencial, procurando ressaltar o compromisso da noção existencial de movimento com uma concepção modal de mudança relacional na existência. Tal concepção também implica a ideia da plasticidade ou não fixidez do passado existencial.

Palavras-chave: Heidegger; historicidade; movimento; mudanças relacionais; propriedades emergentes.

\section{O ENIGMA DO MOVIMENTO}

O problema da historicidade é elaborado em Ser e tempo com uma operação de "construção fenomenológica" que distingue os entes primariamente históricos dos que são secundariamente históricos (HEIDEGGER 1977, p. 497/504). Primariamente históricos são os seres humanos,

\footnotetext{
${ }^{1}$ Recebido: 11-03-2017/ Aceito: 24-07-2017/ Publicado online: 08/02/2018.

${ }^{2}$ Este trabalho recebeu o apoio do CNPq.

${ }^{3}$ Professor titular no Departamento de Filosofia na Universidade Federal de Santa Maria, Santa Maria, RS, Brasil.
} 
entendidos como existência e ser-no-mundo. Os entes intramundanos são secundariamente históricos, e sua historicidade é derivada de sua pertinência a mundo. Dado que "mundo" designa uma determinação ontológica dos seres humanos, vigora uma relação de dependência na historicidade dos entes primária e secundariamente históricos.

No âmbito dos entes primariamente históricos, a historicidade é a mobilidade do acontecer da existência humana. Trata-se do movimento de extensão (Erstreckung) na qual se forma a constância (Ständigkeit) singular de cada ser humano. A forma autêntica da historicidade foi apresentada como uma decisão precursora que, retornando do colapso da significatividade, escolhe livremente uma possibilidade existencial herdada. Subtraída da contingência na projeção em possibilidades casuais, a existência adquire a unicidade e a necessidade do destino ${ }^{4}$. Dada a constituição social da existência, o movimento da existência pessoal acontece em conjunto com outros. Acontecer como destino comum representa o autêntico e pleno movimento da existência (HEIDEGGER 1977, p. 507-408/510). A historicidade inautêntica, por seu turno, consiste no existir de modo impróprio, no qual a projeção em possibilidades acontece sem decisão precursora e sem escolha de uma herança. A existência acontece como uma dispersão contingente na multiplicidade de ocupações, sendo o passado retido como mera factualidade num presente familiar e habitual. A constituição social da decisão ocorre como submissão à interpretação ocorrida que circula impessoalmente como evidente (HEIDEGGER 1977, p. 512/515/517).

Os entes secundariamente históricos são denominados

${ }^{4}$ Sobre a relação entre necessidade e destino, ver Reis (2016). 
de o mundi-histórico (das Welt-geschichtliches). Nesse fenômeno, há dois aspectos indissociáveis: o acontecer de mundo - que implica a admissão de uma historicidade no horizonte de significatividade - e o acontecer a partir de mundo - que se passa com os entes descobertos. Os entes disponíveis e os entes subsistentes (a natureza) são dotados de uma historicidade própria, mas que é dependente da historicidade primária dos entes que são Dasein (HEIDEGGER 1977, p. 513-514). Desse modo, o acontecer da existência é uma mobilidade que afeta o mundo enquanto horizonte relacional de significatividade, sendo condicionante de um acontecer que ocorre com os entes descobertos no mundo. Portanto, também os entes que comparecem no mundo possuem história.

A construção fenomenológica do movimento histórico exibiu, com base na totalidade estrutural do cuidado, a estrutura da mobilidade existencial. Além disso, a temporalidade originária ofereceu a base para apresentar as condições de possibilidade da historicidade. Não obstante, Heidegger declara haver um limite na elucidação do movimento histórico. Não se trata de um limite qualquer, mas de um enigma (Rätsel). Referindo-se ao movimento no âmbito mundi-histórico, ele justifica a falta de aprofundamento na análise porque se tratava, antes de tudo, de conduzir perante "o enigma ontológico do acontecer em geral" (HEIDEGGER 1977, p. 514). Um enigma também se esconde na estrutura temporal da historicidade autêntica, pois nela se evidencia a primazia do passado, na retomada de uma herança, apesar de o presente e o futuro serem igualmente originários na temporalidade da existência (HEIDEGGER 1977, p. 504). Esse mesmo motivo reaparece na interpretação dos modos autêntico e inautêntico da 
historicidade humana:

A interpretação existencial da historicidade do ser-aí resvala constantemente, sem se aperceber, para as sombras. As obscuridades são difíceis de dissipar, porquanto não se distinguiu ainda as possíveis dimensões do questionamento adequado e porque em todas elas opera o enigma do ser e - como agora ficou claro - o do movimento. (HEIDEGGER 1977, p. 517).

Observa-se que, aqui, a expressão "enigma do movimento" está usada em conjunção com "o enigma do ser". Ambos os enigmas seriam responsáveis pelas obscuridades na interpretação da historicidade. Em suma, o resultado da construção fenomenológica chega a um limite importante. Segue-se que a análise do movimento histórico, apesar da interpretação temporal da sua estrutura, não é completa. No restante deste artigo examinarei a possibilidade de identificar mais detalhadamente a natureza desse limite, tomando por base as noções de mudança relacional, emergência de propriedades e não fixidez do passado. $\mathrm{O}$ enigma do movimento poderia ser o reconhecimento de que, no âmbito histórico, ocorre uma dinâmica de emergência relacional de determinações existenciais?

\section{MUDANÇAS RELACIONAIS E NÃO FIXIDEZ DO PASSADO}

David Weberman (1997, 1999, 2000 e 2004) apresentou uma justificativa da hermenêutica de Gadamer argumentando que a dependência do objeto da compreensão em relação ao horizonte da situação hermenêutica é resultante do compromisso com uma ontologia relacionalista. $\mathrm{O}$ objeto da compreensão hermenêutica não seria determinado apenas por suas propriedades intrínsecas, mas é genuinamente qualificado por propriedades relacionais e mudanças 
relacionais genuínas (WEBERMAN 2000, p. 53-56; 2004 p. 271). Exemplos de objetos que desfrutam dessa ontologia seriam os temas da investigação histórica, os valores, as relações de parentesco, as instituições, as obras de arte, as propriedades estéticas e os eventos históricos e passados (WEBERMAN 1997, p. 750-753; 1999 p. 143-144; 2000 p. 51; 2004 p. 267-271). A pretensão de que a ontologia de tais objetos não é redutível ao estrato físico ou psicológico é característica da hermenêutica de Heidegger e Gadamer. De outro lado, a noção de mudança relacional não integra o arsenal fenomenológico e hermenêutico de análise. Entretanto, a principal dificuldade dessa interpretação não é filológica, mas conceitual.

A tese da subdeterminação ontológica depende, em primeiro lugar, da admissão de uma teoria de propriedades que justifique a diferença entre propriedades intrínsecas e propriedades extrínsecas. Propriedades extrínsecas diferem das propriedades intrínsecas por serem propriedades relacionais (LEWIS 1983, p. 197). A aceitação de propriedades relacionais implica, por sua vez, que possam ocorrer mudanças relacionais. Esta concepção foi criticada por Peter Geach (1969 p. 65/71/99), que sustenta que essas mudanças não seriam genuínas, mas fictícias. A expressão "mudança de Cambridge" nomeia a classe de mudanças que não são verdadeiras, ou seja, são relacionais ${ }^{5}$. Quando mudam apenas as propriedades relacionais de um objeto, mas não suas propriedades intrínsecas, então o objeto não sofreu nenhuma mudança real. Logo, as mudanças relacionais não são eventos ou mudanças genuínas.

\footnotetext{
${ }^{5} \mathrm{O}$ termo origina-se da objeção de Geach ao critério de identificação de mudanças que fora definido por Russell e McTaggart em Cambridge.
} 
Weberman (1997) sustenta, ao contrário, que mudanças relacionais podem ser genuínas quando a determinação por propriedades relacionais emergentes integra as condições de identidade de certos entes ${ }^{6}$. $\mathrm{O}$ argumento inclui, por um lado, o reconhecimento de que algumas mudanças relacionais são efetivamente genuínas. Para isso, são oferecidos exemplos relevantes cuja determinação ontológica será inadequadamente concebida caso se excluam como fictícias todas as mudanças relacionais. Por outro lado, o argumento de Weberman sustenta que algumas propriedades relacionais podem ser concebidas como propriedades internas. Desse modo, é necessário um critério para diferenciar mudanças relacionais genuínas de fictícias. A elaboração do critério implica o reconhecimento de que certas propriedades relacionais pertencem às condições de identidade de um tipo de objetos. A individuação desses entes não ocorre, portanto, apenas com base em propriedades intrínsecas, mas também a partir de propriedades relacionais emergentes. Contudo, essa cláusula não é suficiente e precisa ser acrescida de duas exigências adicionais. Em conjunto, elas constituem as condições necessárias e suficientes para que uma mudança relacional seja genuína. $\mathrm{O}$ objeto que experimenta esse tipo de mudança deve estar primeiramente em relação causal com outro objeto. Este, por sua vez, deve ser significativo ou relevante segundo hábitos, costumes, esquemas conceituais e interesses. $\mathrm{O}$ critério para distinguir mudanças relacionais genuínas inclui, portanto, um necessário componente convencional, contingente e normativo. Desse modo, um evento pode mudar de modo relacional não fictício quando contribui causalmente para a

\footnotetext{
${ }^{6}$ Com apoio nos argumentos de Kim (1993) e Lombard (1978).
} 
ocorrência de outro evento que, por sua vez, é avaliado como relevante de acordo com um esquema conceitual, hábitos e estipulações normativas (WEBERMAN 1997, p. 765-766).

Um aspecto relevante que resulta da apresentação do critério para diferenciar mudanças relacionais genuínas repousa na aceitação de entes e propriedades emergentes. Nesse contexto, "emergência" significa que certos entes ou propriedades, mesmo sendo fisicamente corporificados, não são redutíveis às suas propriedades físicas. Propriedades e entes emergentes seriam aqueles para os quais as mudanças relacionais podem ser mudanças genuínas (WEBERMAN 1999, p. 145-147). A formulação desse critério é significativa para a ontologia dos fenômenos sociais e históricos, na medida em que exemplificariam mudanças relacionais derivadas da aceitação de propriedades relacionais emergentes.

Os fenômenos históricos, em relação aos quais é relevante a distância temporal, exemplificam um tipo especial de mudança relacional. De acordo com Weberman (1997), o passado histórico é povoado por fatos e eventos cuja individuação ocorre através de propriedades relacionais emergentes. Daqui resulta a tese contraintuitiva da não fixidez do passado histórico. Ela reza que a distância temporal não promove apenas a mudança epistêmica no intérprete de fenômenos ocorridos, mas uma mudança ontológica no passado. Se a distância temporal proporciona uma mudança relacional genuína, em razão da emergência de novas propriedades relacionais num evento ocorrido anteriormente, então é consistente dizer que o passado não é fixo e pode mudar. É certo que nem todo passado seria dotado dessa plasticidade ontológica. Contudo, o passado histórico, refe- 
rente ao domínio dos fenômenos sociais, psicológicos e existenciais, pode ser visto como não fixo em razão da estrutura relacional derivada das suas condições de identidade, entre as quais figuram as propriedades relacionais emergentes (WEBERMAN 1997, p. 750/754/756, 758-760, 764-767).

Segundo Weberman, a hermenêutica filosófica, ao assumir implicitamente a subdeterminação ontológica do objeto da compreensão, pode ser apresentada com um tipo de relacionalismo emergentista. Nela, também estaria implicada a restrição da tese da fixidez do passado histórico. Tendo definido esse esquema conceitual, examinarei a seguir a pertinência das noções de mudança relacional genuína e não fixidez do passado histórico para identificar o que Heidegger denominou de "o enigma do movimento".

\section{MUdANĢAS RELAGIONAIS NOS ENTES MUNDI- HISTÓRICOS}

A interpretação do movimento histórico com base no esquema de mudanças relacionais e emergência de propriedades satisfaz, em primeiro lugar, o requisito de consistência com o pluralismo ontológico afirmado em Ser e tempo ${ }^{7}$. Reconhecer modos de ser irredutíveis significa admitir diferentes condições de identidade, isto é, diferentes maneiras de individuação e determinação. Portanto, é consistente supor que a individuação não ocorra apenas por instanciação de propriedades internas, mas também com a emergência de propriedades relacionais. Além disso, tam-

\footnotetext{
${ }^{7}$ Sobre o pluralismo ontológico de Ser e tempo, ver McDaniel (2009); McManus (2013); Kelly (2014).
} 
bém é consistente supor que possa haver emergência não apenas de propriedades (internas ou relacionais), mas também de outros tipos de determinações. Em segundo lugar, os modos de ser reconhecidos em Ser e tempo exibem um traço formal relacionalista. Essa concepção significa que a individuação é parcialmente constituída pelas relações que os entes estabelecem com outros entes. Este é, claramente, o caso dos entes disponíveis (Zuhandenes) e dos seres humanos $(\text { Existenz })^{8}$.

Iniciarei a interpretação do movimento histórico com as noções de mudança relacional e emergência de determinações a partir da consideração da dinâmica dos entes secundariamente históricos. Os entes mundi-históricos constituem o domínio dos entes diferentes do ser humano que são descobertos em comportamentos intencionais no mundo. Exemplos de instâncias do domínio mundihistórico são os utensílios, as obras resultantes de seu uso, as instituições, os negócios, as ocupações, os incidentes e os acidentes que se conjugam com utensílios e obras, a natureza pertencente ao mundo circundante, as paisagens, os locais de assentamento, a exploração e o culto, os campos de batalha etc. (HEIDEGGER 1977, p. 504/512-514).

A historicidade dos entes mundi-históricos consiste na estrutura de um movimento específico, porque, segundo Heidegger, o que acontece com utensílios e obras possui uma característica própria de mobilidade que não pode ser concebida com a noção física de movimento, isto é, como mudança de lugar. $\mathrm{O}$ mesmo valeria para processos e acontecimentos intramundanos e, em certo sentido, também pa-

\footnotetext{
${ }^{8}$ Weberman (2001 p. 109-110/117-120) mostrou de modo convincente que o relacionalismo estende-se para além do modo da existência (Existenz) e da disponibilidade (Zuhandenheit), mas também é integrante das condições de identidade no modo da subsistência (Vorhandenheit).
} 
ra as catástrofes naturais (1977 p. 514). Determinar se o específico dessa mobilidade consiste em integrar mudanças relacionais derivadas da emergência de propriedades relacionais exige, inicialmente, um exame de cada um dos casos mencionados. Heidegger indicou um exemplo que é relevante nesse contexto.

Um anel que é entregue (presenteado) e carregado (levado, usado) sofre uma mudança que não é apenas a alteração de lugar (HEIDEGGER 1977, p. 514). Com ele não ocorreu apenas um movimento físico, mas uma mudança adicional. Note-se que o caso exemplifica uma mudança no anel e não no seu donatário ou portador. A ênfase posta na conjunção de "ser entregue" e "ser carregado", sublinhada com a expressão "neste seu ser" entregue e carregado, indica que a alteração no anel seria uma dupla mudança relacional: o anel $r$ ser entregue por uma pessoa $b$ à pessoa $c$ e também o anel $r$ ser usado pela pessoa $c$. Ao figurar conjuntamente nessas duas relações, o anel sofre uma dupla mudança relacional. De fato, ele sofre infinitas mudanças relacionais, mas todas elas são casos de mudanças de Cambridge, ou seja, não seriam mudanças genuínas. Que tipo específico de mudança estaria sendo visada nesse caso, que exemplifica a historicidade ou mobilidade de um ente intramundano?

Apesar de não ter examinado em detalhe o exemplo, é plausível supor que Heidegger não tivesse em vista esse tipo peculiar de mudança relacional (derivada da conjunção de duas relações), pois ela resulta de uma análise formal que desconsidera o modo específico de ser de um anel, que é a disponibilidade (Zuhandenheit). Entendido como um utensílio, que mudança pode ser identificada no anel a partir da conjunção de ser entregue e ser levado? No modo de ser da 
disponibilidade, a identidade é constituída relacionalmente por quatro remissões: ao usuário médio, a outros utensílios, ao material de que é feito e à série teleológica de metas finalizada em um resultado ou obra vinculada a uma possibilidade existencial. A conjunção relacional não altera significativamente o material de que é feito o anel. As mudanças relacionais que afetam a remissão ao usuário e aos demais utensílios associados também aparentam ser meras mudanças de Cambridge. A mudança histórica no anel deve ser identificada, portanto, nas alterações que tenham ocorrido nas remissões às metas e aos produtos a que serve o anel.

A despeito da antiguidade e da diversidade de formas, materiais e utilizações, os anéis são peças ornamentais produzidas na arte joalheira. Como utensílios ornamentais usados no corpo (em geral nos dedos da mão), geralmente os anéis pertencem à classe particular de utensílios que Heidegger denomina de sinais (Zeichen). Sinais são utensílios para mostrar (HEIDEGGER 1977, p. 103), e os anéis também servem para isso: mostrar um estado civil, um grau acadêmico, uma profissão etc. No exemplo, o anel foi entregue, não achado ou roubado; ele é usado, não guardado, escondido ou limpo. Conclui-se que o anel está sendo usado adequadamente, cumprindo sua meta: mostrar. O anel foi entregue para mostrar e está sendo carregado para mostrar: ele remete ao doador e ao portador, mostrando uma decisão, uma promessa, uma graduação etc. Uma manifesta mudança ocorrida com o anel é a alteração no estado de simplesmente estar pronto para uso (aprontado pelo joalheiro e aguardando a entrega), passando para o estado de uso efetivo após a concessão. $\mathrm{O}$ anel está sendo usado para mostrar, ele foi levado pela ação de um agente 
externo até sua meta teleológica. A característica disposicional de poder mostrar foi atualizada com a intervenção de um agente externo. $\mathrm{O}$ exame dessa mudança revelará, no entanto, um aspecto não tão trivial da mobilidade histórica dos utensílios.

Um evento experimenta uma mudança relacional genuína quando entra em uma série de conexões causais que proporcionam a ocorrência de outro evento, que, por sua vez, é considerado relevante. Se um evento passado contribuiu causalmente para a ocorrência no futuro de outro evento, e se este evento é avaliado como relevante, então a ocorrência do evento futuro pode fazer emergir uma nova propriedade relacional no evento passado. O evento passado mudou relacionalmente de forma genuína em razão do evento futuro. No caso do anel usado para mostrar, há uma mudança que ocorre com o próprio anel na medida em que ele é posto em um campo relacional mais específico. Ele é inserido no domínio de relações causais que podem conduzir ao surgimento de entes ou eventos, os quais, por sua vez, podem estar sob as condições de relevância. Em outros termos, o anel que mostra é um elemento num encadeamento causal e motivacional que pode promover uma mudança relacional genuína. Ao ser posto no campo das mudanças relacionais genuínas, o anel ganhou uma nova determinação: ele tornou-se apto, adequado, apropriado para promover mudanças relacionais genuínas. Essas mudanças referem-se à emergência de propriedades relacionais. Assim, o anel sofreu uma mudança porque ganhou uma nova determinação, a saber, a de ser capaz de fazer emergir propriedades relacionais. Essa é uma nova determinação importante, pois o anel habilita-se, por exemplo, a contribuir para o surgimento de eventos que podem mudar 
o passado. $\mathrm{O}$ uso do anel é integrante da cadeia que permite a emergência de propriedades retardadas. Diferentemente de seu Doppelgänger na mão de Gyges, o anel não é mágico, mas pode deixar emergir certas propriedades atrasadas e não apenas “invisíveis" no presente, contribuindo, por exemplo, para a não fixidez e plasticidade do passado.

Em termos gerais, o uso eficaz de um utensílio modifica o próprio utensílio porque lhe confere uma determinação nova que consiste na aptidão para promover mudanças relacionais genuínas, inclusive aquelas que mudam o passado. Segundo essa análise, portanto, a historicidade dos utensílios refere-se em parte à sua virtual capacidade de contribuir para a ocorrência de verdadeiras mudanças relacionais, sendo capazes, inclusive, de promover mudanças no passado. Por certo, a interpretação do movimento histórico dos entes intramundanos com base na emergência de propriedades relacionais precisa ser estendida às demais classes de entes mundi-históricos. Não obstante, muitos dos exemplos oferecidos por Heidegger referem-se exatamente aos tipos de entes que são apresentados por Weberman como possuindo uma identidade relacional determinada por propriedades emergentes. Se, por hipótese, o exame for bem-sucedido em mostrar que os casos elencados por Heidegger são exemplos de entes com identidade relacional emergente, então haveria um indício favorável para considerar que a peculiaridade do movimento intramundano reside da emergência de determinações relacionais. Sendo mais exato, há um movimento próprio que acontece nos entes intramundanos quando eles estão presentes em comportamentos intencionais apropriados: eles são postos nas relações capazes de deixar emergir propriedades e mudanças relacionais. No entanto, conforme ressaltou Heidegger 
(1977 p. 504), os entes intramundanos são históricos porque pertencem a mundo. A historicidade do mundihistórico inclui, além do movimento dos entes intramundanos, um movimento específico de mundo.

\section{MUDANÇAS RELACIONAIS E HISTÓRIA DO MUNDO}

Os entes intramundanos estão incorporados na história do mundo (Geschichte der Welt). Mundi-história (Weltgeschichte) também acontece a cada vez com a existência fáctica de entes que são ser-aí (HEIDEGGER 1977, p. 513/520). Não apenas os entes mundi-históricos, mas o mundo como tal também possui história. A mobilidade do mundo pode ser identificada na historicidade das antiguidades preservadas em museus. As coisas de museus exibem, nas evidências de sua perecibilidade, uma mudança. Além das mudanças do perecer, também há o fato de que, sendo utensílios, estão fora de uso. No entanto, o que nelas se evidencia como uma mudança propriamente histórica é que o mundo a que pertenciam passou. A trama utensiliar de um utensílio preservado no museu sofreu uma dinâmica: aquele mundo não é mais. Num museu, pode-se perceber uma conjunção muito especial, que é a subsistência de entes intramundanos de um mundo que não existe mais (HEIDEGGER 1977, p. 502-503/520). Nesse sentido, num museu está exibida uma história de mundo (e não apenas de entes): o movimento extremo de um mundo que deixou de ser.

Para analisar essa dinâmica (mas não apenas no caso do deixar de existir de um mundo), é preciso considerar os momentos formais do fenômeno do mundo: 1) ser uma totalidade de relações de significatividade; 2) estruturar os 
comportamentos intencionais que descobrem entes na estrutura do algo enquanto algo; 3) vincular-se a uma possibilidade existencial em que se projetam seres humanos fácticos. A dinâmica nesses momentos perfaz, portanto, a mobilidade especifica da história do mundo. Mudanças ocorrem na totalidade de relações de significatividade, por exemplo, de ampliação ou redução. Nessa direção, podem ocorrer modificações específicas em razão de mudanças na compreensão de modos de ser que integram a totalidade de significatividade. Formalmente, a dinâmica acontece na unidade mereológica do todo de relações de significatividade. Também na função de abertura pode acorrer uma dinâmica específica, afetando a estrutura da intencionalidade dos comportamentos. A mobilidade pode acontecer no eixo da expressividade da vinculação a mundo quando a função de abertura modifica-se de uma ocorrência tácita para um modo temático e interpretado. Com isso, inicia-se uma dinâmica hermenêutica na qual as interpretações de mundo são elas mesmas modificadas. Também pode acontecer um movimento na direção da assignificatividade, ou seja, a suspensão da função de abertura. O colapso na função de descobrimento é uma dinâmica de perda e retomada da significatividade nos comportamentos intencionais ${ }^{9}$. Por fim, há uma mobilidade de mundo no tocante ao vínculo das relações de significatividade com a projeção em possibilidades existenciais. A mudança pode se dar em relação às possibilidades vinculadas ou à projeção. As coisas de museu exemplificam o caso extremo da mudança na projeção. Um mundo que passou é uma totalidade de relações de

\footnotetext{
${ }^{9}$ Sob esse ponto de vista, a interpretação de sintonias como angústia e tédio integra a elucidação da história do mundo.
} 
significatividade vinculadas a uma possibilidade que deixou de ser existencial, pois nela ninguém se projeta mais.

Considerando a interdependência dos três momentos do fenômeno do mundo, uma dinâmica específica em cada um deles afeta a história do mundo como um todo. A projeção em possibilidades existenciais diferentes acarreta uma mudança na significatividade e na descoberta intencional de entes. Do mesmo modo, a relação entre diferentes possibilidades existenciais pode gerar mudanças nas respectivas projeções existenciais. Seria correto inferir que também os entes intramundanos podem ocasionar uma mobilidade no mundo, dado que apenas neles existem facticamente as relações de significatividade ${ }^{10}$. A interpretação da historicidade de mundo precisa incluir, portanto, uma análise dessas relações de dependência.

Além dessa dificuldade, a análise da dinâmica de mundo com base nos conceitos de mudança relacional genuína deve observar que, nesse caso, as mudanças e a emergência aconteceriam no todo de relações de significatividade. Relações de segunda ordem seriam responsáveis por mudanças relacionais na estrutura do mundo. Aceitando essa hipótese, não apenas os entes intramundanos poderiam mudar relacionalmente, mas haveria uma historicidade referente à emergência de determinações relacionais de mundo. Nesse marco, também os mundos passados seriam capazes de mudanças ao estarem em relações com outros mundos futuros. Uma dificuldade dessa concepção é que, seguindo o critério de Weberman, seria preciso admitir conexões causais entre relações de significatividade. Outra

\footnotetext{
${ }^{10}$ Por exemplo, a descoberta de que chimpanzés produzem e usam instrumentos promove uma mudança nos significados de utensílio e de ser humano.
} 
perspectiva seria postular que, entre as totalidades de significatividade, poderia subsistir um tipo de dependência não causal mais ampla do que a estritamente lógica ${ }^{11}$. Aparentemente, não há uma inconsistência conceitual que impeça o exame dessas hipóteses.

Não obstante, o mundo é histórico porque é uma determinação do ser humano entendido como ser-no-mundo (HEIDEGGER 1977, p. 504). A mobilidade de mundo e dos entes intramundanos é dependente da mobilidade e da historicidade do ser humano. Para interpretar a mobilidade propriamente humana com o esquema de mudanças relacionais por emergência de determinações, destacarei a seguir alguns aspectos da historicidade existencial.

\section{MOBILIDADE E MODALIDADE DA HISTORICIDADE AUTÊNTICA}

A interpretação do movimento na existência humana é a articulação conceitual da dinâmica que determina os seres humanos como históricos. Cada ser humano é este movimento (HEIDEGGER 2016a, p. 153). Tal dinâmica não é uma adição ou conexão de vivências, mas um estender-se, um prolongar-se no qual cada existente chega a uma permanência. Não sendo determinado por propriedades, o serhumano tem na sua mobilidade histórica a maneira específica em que acontece a individuação existencial. O estender-se da existência encontra permanência em dois modos: dispersão (Zerstreuung) e constância (Ständigkeit). O resultado da interpretação desse movimento, com base na unidade das estruturas do cuidado e na temporalidade

\footnotetext{
${ }^{11}$ Sobre a dependência não causal, ver Kim (1993).
} 
originária, diferencia dois modos do acontecer individualizador da existência humana: a historicidade autêntica e a inautêntica.

O movimento inautêntico acontece na cotidianidade mediana. Nela, os seres humanos projetam-se nas possibilidades existenciais ligadas à ocupação com entes intramundanos. O movimento é determinado pela multiplicidade do que se passa nas ocupações cotidianas. A individuação ocorrida é de um si mesmo disperso e inconstante, cuja regulamentação é fornecida pela estabilidade impessoal do "a gente" (das Man, HEIDEGGER 1977, p. 515/517). A historicidade autêntica, por seu turno, é uma individuação que forma constância na existência. Seu elemento básico é a decisão precursora da morte ${ }^{12}$. Esse movimento acontece a partir do colapso de uma identidade prática no qual o projeto em uma possibilidade existencial perde força vinculativa. Nele, conjugam-se quatros aspectos: o retorno ao contexto intencional em que alguém existe em relação com outras pessoas e entes; o momento epistêmico de abertura de um horizonte modal no interior do qual são achadas as possibilidades da decisão; a escolha livre de uma possibilidade existencial herdada; e a transmissão da possibilidade escolhida. Em suma, o movimento na existência autêntica acontece como uma decisão em que a escolha de possibilidades herdadas, numa situação epistemicamente ampliada, leva à constância formada por uma vinculação não contingente à significatividade (HEIDEGGER 1977, p. 505507/516).

A constituição social da historicidade também é ressal-

\footnotetext{
${ }^{12}$ Há uma extensa literatura sobre o conceito existencial de morte. Adoto aqui a análise oferecida por Thompson (2013).
} 
tada na interpretação da mobilidade da existência. Dada a estrutura de socialidade da existência, então não apenas a significatividade de mundo e da intencionalidade é compartilhada, mas também o acontecer da individuação é determinado pela socialidade. Isso significa, inicialmente, que o acontecer de uma pessoa é em conjunto com o acontecer de outras. Além disso, Heidegger também admite um movimento que não é apenas de indivíduos, mas de grupos. $\mathrm{O}$ movimento próprio de grupos é um fator de determinação no acontecer individual, no sentido de que as decisões são conduzidas pela mobilidade grupal (HEIDEGGER 1977, p. 508). Essa determinação deve ser compreendida hermeneuticamente, na medida em que a interpretação ocorrida (Ausgelegtheit), que vigora na situação hermenêutica de uma geração, regula a historicidade da existência individual no seu acontecer autêntico e inautêntico (HEIDEGGER 2004, p. 88-89) ${ }^{13}$.

A interpretação da historicidade oferecida em Ser e tempo permite identificar, ademais, uma dimensão modal na mobilidade existencial. A despeito de também estar presente no modo inautêntico, essa dimensão é especialmente manifesta na forma autêntica da historicidade. A característica modal é manifesta nos aspectos formais da decisão: transmissão de herança, escolha de possibilidade, abertura do horizonte modal e retorno à situação. Quando fundada na decisão precursora no ser-para-a-morte, a descoberta e a escolha acontecem de modo inequívoco e não contingente

\footnotetext{
${ }^{13} \mathrm{O}$ conceito da geração, explicitamente retirado da obra de Dilthey, é introduzido para apresentar uma determinação formal da historicidade existencial (HEIDEGGER 1977, p. 508; 2016b p. 153). Para o objetivo deste artigo, não é necessário entrar na discussão sobre a legitimidade fenomenológica da admissão de uma historicidade de grupos, comunidades e povos (CROWELL 2004, p. 69-70).
} 
(unzufällig), excluindo as possibilidades contingentes. Sob esses dois aspectos, a historicidade autêntica é a formação de necessidade existencial. De outro lado, quando a herança é transmitida expressamente, acontece uma retomada do possível que não é a repetição de uma efetividade ocorrida no passado, mas uma resposta (Erwiderung) à possibilidade existencial. Por fim, a retomada do possível promove uma despresentificação (Entgegenwärtigung) e desabituação (Entwöhnung) do que é atual e usual na situação da decisão (HEIDEGGER 1977, p. 517). O retorno à situação intencional introduz uma diferença crítica na interpretação ocorrida, retirando o primado da regulamentação impessoal na qual o possível existencial está subordinado à efetividade subsistente. Conclui-se, em resumo, que a individuação por constância de si mesmo, que é o movimento na historicidade autêntica, possui o sentido modal de uma prevalência do possível sobre o efetivo. Tendo em vista $\mathrm{o}$ aspecto modal do movimento existencial, que precisa ser examinado mais detalhadamente, apresentarei a seguir uma interpretação da mobilidade histórica com base nos conceitos de mudança relacional e emergência de determinações.

\section{MUDANÇAS RELACIONAIS NA HISTORICIDADE PRIMÁRIA}

Dado que, no modo de ser da existência, a determinação dos entes não acontece por instanciação de propriedades, o modelo emergentista precisa ser ampliado para incluir o surgimento de determinações que não sejam propriedades, mas possibilidades existenciais. Assim, no modo de ser da existência, o conceito de mudança relacional designa uma mudança resultante de uma relação cujos termos são proje- 
ções em possibilidades existenciais. Naturalmente, é correto pensar numa relação que vincule a projeção em uma possibilidade existencial com eventos ou fatos. Contudo, a factualidade na existência é subdeterminada, porque a efetividade factual é relativa à determinação segundo possibilidades existenciais (HEIDEGGER 1977, p. 75).

O conceito de mudança relacional na existência designa, além disso, uma modificação nas possibilidades existenciais relacionadas. Essa mudança deve ser identificada nas características formais da possibilidade existencial ${ }^{14}$. De acordo com a analítica existencial, as possibilidades mantêm sua determinação existencial apenas e tão somente quando acontece a projeção, e não quando são tematizadas ou planificadas. Além disso, as possibilidades existenciais são finitas, no sentido de que sua força de vinculação é internamente exposta ao colapso. Por fim, possibilidades existenciais são internamente relacionais porque a projeção em uma possibilidade determinada sempre inclui e exclui outras possibilidades. As possibilidades existenciais são dotadas de uma característica conjuntiva e disjuntiva, isto é, em cada possibilidade existencial há simultaneamente um excesso e uma carência de outras possibilidades existenciais. A alteração nas duas primeiras características retira o modo especificamente existencial das possibilidades. Portanto, mudanças relacionais no âmbito existencial afetam o aspecto conjuntivo-disjuntivo do possível existencial. A mudança nesse aspecto pode ser um aumento ou decréscimo tanto nas possibilidades existenciais conjugadas na projeção como naquelas excluídas. A noção de mudança relacional significa, em suma, uma modificação na característica conjunti-

\footnotetext{
${ }^{14}$ Para uma análise da noção de possibilidade existencial, ver Reis (2014).
} 
vo-disjuntiva de uma possibilidade existencial em razão de que a projeção nela esteja em relação com o projeto em outra possibilidade existencial.

No entanto, aparentemente é necessário um critério para diferenciar as mudanças relacionais genuínas em relação ao análogo existencial das mudanças de Cambridge. Também no contexto existencial, nem todas as mudanças relacionais são genuínas. Nesse sentido, um critério pode ser formulado por analogia com o critério fornecido por Weberman para identificar mudanças genuínas na relação temporal entre um evento passado e outro posterior. A condição necessária é que o evento anterior pertença a um encadeamento causal responsável pela ocorrência do evento posterior, e a condição suficiente consiste nas propriedades normativas do evento posterior, isto é, que ele seja considerado relevante segundo um esquema conceitual, convenções e avaliações de um grupo humano. De modo similar, a condição necessária para que um projeto em uma possibilidade existencial $\left(\mathrm{P}^{1}\right)$ sofra uma mudança na sua característica conjuntivo-disjuntiva, em razão de estar numa relação com outro projeto em uma possibilidade existencial $\left(\mathrm{P}^{2}\right)$, consiste em que $\mathrm{P}^{1}$ pertença à situação hermenêutica em que está lançada aquela pessoa que efetua $\mathrm{P}^{2}$. No entanto, a pertinência à situação de projeção de $\mathrm{P}^{2}$ não é suficiente, mas também é preciso que $\mathrm{P}^{2}$ seja uma resposta prolongada até $\mathrm{P}^{1}$. Essa é a condição necessária para a ocorrência de mudanças relacionais genuínas no campo existencial. Note-se que essa condição não significa a eliminação da opacidade que caracteriza a situação hermenêutica de projeção em possibilidades existenciais. Ela estabelece, antes disso, uma relação de prolongamento entre projetos em possibilidades existenciais, uma extensão 
que preserva a determinação existencial das possibilidades relacionadas.

No entanto, tal condição não é suficiente. No critério de Weberman, a emergência de propriedades relacionais no evento anterior depende de o evento posterior ter certas caraterísticas de relevância. $\mathrm{O}$ análogo existencial dessa condição adicional estabelece que um projeto em possibilidade existencial é capaz de ocasionar uma mudança relacional em outro projeto existencial caso se revista de uma característica existencialmente relevante, e não apenas em função de convenções, hábitos e esquemas conceituais de um grupo. A condição deve ser estritamente existencial, no sentido de que $\mathrm{P}^{2}$ constitui a formação de uma constância de si a partir do colapso da significatividade. Quando $\mathrm{P}^{2}$ satisfaz essa condição, então se habilita a estar numa relação capaz de promover uma mudança relacional em $\mathrm{P}^{1}$. Em resumo um projeto existencial pode sofrer uma mudança relacional genuína caso uma relação de continuidade o vincule com o projeto com o qual alguém se individua de modo expresso a partir de sua própria finitude. Dito no léxico da analítica existencial, o ser para a morte representa o fundamento oculto da possibilidade de mudanças relacionais genuínas no campo da existência humana.

Com base nesse conceito existencial de mudança relacional genuína, e tendo em vista a dimensão modal da historicidade em geral, sugere-se que o contexto específico para o acontecimento de mudanças relacionais genuínas é o da historicidade autêntica. $\mathrm{O}$ acontecer autêntico, como foi visto, é a formação de uma individuação por constância de si mesmo, operada como retomada e resposta (Erwiderung) a uma possibilidade herdada que está presente na situação da decisão. Além de preservar o estatuto existencial 
da possibilidade herdada, a decisão acontece a partir daquela incorporação da finitude da possibilidade que somente o colapso da significatividade é capaz de proporcionar. Assim, o movimento próprio da historicidade autêntica na existência humana não constitui uma prevalência do possível apenas em razão da retomada do possível herdado, mas também porque é uma dinâmica capaz de promover mudanças relacionais genuínas nas possibilidades existenciais. É o movimento que retoma e preserva o possível como possível, ou seja, habilita a mudança por emergência de novas determinações nas possibilidades existenciais. Em resumo, uma possibilidade herdada pode mudar relacionalmente na medida em que sua posterior retomada, na decisão que transmite a herança, promove uma mudança imanente na característica conjuntivodisjuntiva da possibilidade existencial. Aqui já se insinua uma consequência da admissão de mudanças relacionais na existência: a plasticidade do passado existencial.

\section{A NÃO FIXIDEZ DO PASSADO EXISTENCIAL}

No modelo de Weberman, o critério para identificar mudanças relacionais genuínas permite justificar a tese da não fixidez do passado. O passado histórico pode mudar, pois, ao entrar em relações específicas com eventos futuros, é capaz de experimentar a emergência de propriedades relacionais relevantes. A emergência de propriedades relacionais atrasadas significa a plasticidade e subdeterminação do passado histórico. Considerando a ampliação existencial do conceito de mudança relacional, também se pode inferir que o passado existencial não é fixo, mas pode sofrer mudanças relacionais genuínas. Nesse caso, a relação entre 
projetos em possibilidades existenciais também é caracterizada pela distância temporal, orientando-se por uma noção serial de tempo. Note-se que, segundo a analítica existencial de Ser e tempo, a intratemporalidade é tão originária quanto a historicidade (HEIDEGGER 1977, p. 498). Logo, a noção serial de tempo possui uma limitada, porém legítima, significação no modo de ser da existência. Isso implica que não incorre em transgressão categorial o entendimento de que a relação com o passado existencial, que acontece na retomada do possível, também seja uma relação determinada como distância temporal.

De um ponto de vista temporal, a distância no tempo, própria da relação que é capaz de promover a emergência de propriedades relacionais atrasadas, está fundada na temporalidade originária. Nesse sentido, não é exatamente a distância temporal que permite a emergência de possibilidades no passado existencial, mas a temporalidade originária do ser-aí. Essa dependência temporal é registrada em Ser e tempo:

Mas se a distância "temporal" em relação ao agora e ao hoje não tem nenhum significado constitutivo para a historicidade do ente propriamente histórico, não é porque este ente não esteja "no tempo" e seja atemporal, mas porque ele existe de modo tão originariamente temporal como jamais poderá sê-lo por sua essência ontológica algo subsistente, que está passando ou vindo "no tempo”. (HEIDEGGER 1977, p. 504-505).

Considerando o movimento da historicidade autêntica, trata-se, pois, da retomada de possibilidades existenciais dos antepassados, de projetos existenciais já ocorridos outrora. Se o passado existencial pode ser datado sem perder sua característica existencial, então ele também oferece um campo para mudanças relacionais genuínas. Para analisar 
o tema é preciso considerar inicialmente uma distinção fundamental no significado da expressão "passado existencial". O passado factual da existência abrange os acontecimentos, decisões e fatos relativos a um existente humano individual. No modelo de Weberman, esses eventos integram o domínio do passado histórico que pode sofrer mudanças relacionais genuínas. Esses eventos são subdeterminados ontologicamente. No entanto, há um estrato mais básico de subdeterminação que não corresponde apenas à limitação das propriedades intrínsecas na constituição da identidade existencial. No modo da existência, o factual é subdeterminado porque é relativo às reais determinações existenciais, a saber, às possibilidades existenciais. Essa concepção é expressa nitidamente quando Heidegger caracteriza o domínio de objetos da historiografia, afirmando que a ciência da história não investiga os fatos ocorridos no passado, mas as possibilidades existenciais:

Mas que significa que o ser-aí seja "factualmente"? Se o ser-aí somente é "propriamente" efetivo na existência, então sua "factualidade" sem dúvida constitui-se precisamente no projetar-se decidido em um poder-ser escolhido. Mas então o própria e "factualmente" sido-aí (Dagewesene) é a possibilidade existenciária na qual se determinaram facticamente destino, destino comum e historia do mundo. (HEIDEGGER 1977, p. 521).

Da primeira sentença infere-se que a factualidade de um ser humano, incluída também sua factualidade passada, é constituída no contexto de uma projeção em uma possibilidade existencial. Há, portanto, uma dependência de constituição do factual em relação ao possível existencial. Mais exatamente, o factual é constituído na projeção decidida em uma possibilidade herdada livremente escolhida, ou seja, na historicidade autêntica. A frase final estende 
a dependência de constituição para todos os possíveis domínios factuais da existência, ou seja, para a individuação constante singular e grupal, bem como para a história do mundo e dos entes intramundanos.

Para o ponto em questão, não obstante, a passagem citada implica que o passado existencial deve ser entendido como estratificado, sendo o nível originário determinado pelas possibilidades existenciais. Assim sendo, o problema da não fixidez do passado existencial refere-se à perspectiva de uma mudança relacional nas possibilidades existenciais. Se esse for o caso, então as próprias possibilidades existenciais também seriam subdeterminadas, e uma herança de possibilidades poderia sofrer uma mudança relacional ao ser transmitida. Em consonância com a noção de mudança relacional genuína no âmbito existencial, quando o passado de projeções em possibilidades existenciais é retomado e transmitido, na situação de uma decisão que incorpora a finitude do possível, são satisfeitas as condições para que ocorra uma mudança relacional genuína. Desse modo, a decisão não apenas abre um horizonte de possibilidades herdadas, mas também habilita uma mudança na própria possibilidade escolhida. $\mathrm{O}$ passado existencial mudaria relacionalmente porque a característica conjuntivo-disjuntiva da possibilidade existencial sofreria uma mudança com a retomada de uma herança na decisão. Haveria, portanto, a emergência nas possibilidades existenciais e uma plasticidade modal, e não apenas factual, no passado existencial.

Essa concepção implica que o passado existencial não é único, ao ser constituído por um âmbito diverso de possibilidades existenciais. Contudo, além de não ser único, o pas- 
sado existencial também não é fixo ${ }^{15}$. A pluralidade e a não fixidez não pertencem apenas ao futuro porque também a herança de possibilidades pode sofrer uma genuína mudança relacional ao ser transmitida numa decisão fundada no ser-para-a-morte. As mudanças relacionais no passado histórico abrangeriam, por conseguinte, as emergências de propriedades relacionais nos eventos ocorridos, mas também a emergência de possibilidades nas heranças modais que são transmitidas. $\mathrm{O}$ passado existencial pode mudar do mesmo modo como muda a existência de um indivíduo ou de um grupo.

\section{CONCLUSÃo}

Caso a precedente interpretação seja plausível, então o movimento do acontecer da existência humana seria, em parte, uma dinâmica de emergência de possibilidades existenciais. No modo inautêntico, a relação com o passado é pautada pela primazia do efetivo sobre o possível, portanto, sem a projeção em possibilidades fundada no colapso da significatividade. $\mathrm{O}$ esquecimento do possível consiste, assim, numa relação que veda as mudanças relacionais nas possibilidades herdadas. Por outro lado, a formação de uma constância de si mesmo a partir da retomada decidida de uma possibilidade existencial é precisamente a abertura para a modificação relacional na herança. A constância de si mesmo corresponde, desse modo, a um tipo de necessidade existencial compatível com a emergência de possibilidades no passado existencial. Naturalmente, dada a

\footnotetext{
${ }^{15}$ Essa determinação formal do passado histórico e existencial como não sendo nem único nem fixo representa uma limitação decisiva na equiparação da noção de historicidade de Ser e tempo com aquela de Hitler (FRITSCHE 1999, p. 19).
} 
dependência dos entes secundariamente históricos em relação à historicidade originária da existência, as mudanças relacionais por emergência de propriedades relacionais também estariam presentes, de uma maneira específica, no acontecer de mundo e dos entes intramundanos. $\mathrm{O}$ movimento histórico seria, ao menos sob um aspecto relevante, uma dinâmica de emergência de propriedades relacionais e de possibilidades existenciais condicionada pela incorporação da finitude das possibilidades na escolha feita em situação. Evidentemente, a plasticidade modal da existência (que não está limitada à dependência serial no tempo) possui consequências robustas para a análise dos comportamentos intencionais para com os entes. Basta considerar, por exemplo, que a opacidade na condição existencial de estar jogado em uma situação (WHITY 2011) é aumentada com a não fixidez do passado histórico.

Note-se que a presente interpretação consiste apenas num esboço a ser analisado mais detalhadamente. A ampliação da base para a interpretação relacional-emergentista deveria incluir um exame mais completo da dimensão modal da historicidade existencial. A estruturação social da historicidade, por sua vez, representa um campo especialmente apropriado para a identificação de mudanças relacionais por emergência de possibilidades existenciais. Já na historicidade inautêntica, em que a escolha existencial é delegada para a regulamentação impessoal, não haveria nenhuma dinâmica de emergência? A emergência de determinações existenciais a partir de mudanças relacionais faria parte do fenômeno que Heidegger denominou "a força silenciosa do possível” (HEIDEGGER 1977 p. 521)? Naturalmente, a justificação da interpretação não teria consequências triviais para o problema da adequação onto- 
lógica e epistemológica da tematização teórica do movimento histórico como um todo. De fato, as consequências de uma análise emergentista da historicidade teriam uma repercussão geral no próprio conceito existencial de ciência.

Para terminar, reporto-me ao problema do "enigma do movimento". A presente interpretação da historicidade não soluciona, mas situa o enigma no domínio específico da emergência de determinações existenciais. A dinâmica modal e as mudanças relacionais genuínas no âmbito da existência representariam o campo de problemas a serem examinados numa interpretação fenomenológica mais completa da historicidade humana. Nesse ponto, além de todas as dificuldades trazidas com a noção de emergência, vincula-se o problema dos limites da historicidade. Friedrich Gottl (1904 p. 5) formulou esse problema como a pergunta sobre onde termina o acontecer histórico: onde o histórico se perde em algo diferente e o que seria essa alteridade do histórico? Por analogia, os limites da historicidade existencial poderiam ser buscados em duas direções: nos condicionamentos of erecidos por dinâmicas históricas originadas de outros modos de ser (história natural, evolutiva etc.) ou na dinâmica de abertura ou fechamento dos próprios modos de ser na compreensão de ser. Visto a partir do surgimento de determinações existenciais com base em mudanças relacionais genuínas, na primeira direção de limitação o problema consiste em determinar se a emergência de possibilidades existenciais sofreria algum tipo de condicionamento não histórico. Na segunda fronteira dos limites do histórico haveria o condicionamento da historicidade existencial pela historicidade da abertura dos modos de ser. Trata-se de uma história específica do ser-aí nos humanos (HEIDEGGER 2016b, p. 237). Nesse caso, a 
historicidade da compreensão de ser e a metafísica do ser-aí poderiam ser interpretadas com base no conceito de emergência ${ }^{16}$ ? Independentemente das respostas a esses problemas, percebe-se nos limites do histórico, talvez como um indicativo favorável, a presença renovada de um aspecto modal: o elemento da necessidade existencial.

Abstract: In this paper, I present an interpretation of the historical mobility of existence according to Heidegger's existential analytic of Being and Time. The interpretation is based on a conceptual framework that includes the notions of relational change and emergent determination. Following an analogue of David Weberman's criterion for genuine relational changes, I shall examine the mobility of existential historicity, aiming to emphasize the commitment of the existential notion of movement with a modal conception of relational change in existence. This conception also entails the idea of plasticity or non-fixity of the existential past.

Keywords: Heidegger; historicality; movement; relational changes; emergent properties.

\section{REFERÊNCIAS}

CROWELL, Steven. Authentic historicallity. In: CARR, D.; CHEUNG, C.-F. Space, time, and culture. Dordrecht: Kluwer Academic Publishers, 2004, p. 57-71.

FRITSCHE, Johannes. Historical Destiny and National Socialism in Heidegger's Being and Time. Berkeley: University of California Press, 1999.

GEACH, Peter. God and the Soul. London: Routledge and Kegan Paul, 1969.

GOTTL, Friedrich. Die Grenzen der Geschichte. Leipzig:

\footnotetext{
${ }^{16}$ Sobre a metafísica do ser-aí, ver Jaran (2010). Para uma interpretação emergentista da problemática ontológica de Ser e tempo, ver McDonough (2006, p. 51-59/60-63).
} 
Duncker \& Humblot, 1904.

HEIDEGGER, Martin. Wilhelm Diltheys Forschungsarbeit und der gegenwärtige Kampf um eine historische Weltanschauung. In: HEIDEGGER, M. Vorträge. Teil 1: 1915-1932. Frankfurt: Vittorio Klostermann, 2016a, p. 215-251.

. Philosophische Anthropologie und Metaphysik des Daseins. In: HEIDEGGER, M. Vorträge. Teil 1: 19151932. Frankfurt: Vittorio Klostermann, 2016b, p. 105-157.

- Der Begriff der Zeit. Frankfurt: Vittorio Klostermann, 2004.

$\overline{1977}$

. Sein und Zeit. Frankfurt: Vittorio Klostermann,

JARAN, François. Toward a Metaphysical Freedom: Heidegger's Project of a Metaphysics of Dasein. International Journal of Philosophical Studies, 18(2), p. 205-227, 2010.

KELLY, Howard. Heidegger the metaphysician: modesof-being and Grundbegriffe. European Journal of Philosophy, 24(3), p. 670-693, 2014.

KIM, Jaegwon. Noncausal connections (1973). Republicado em KIM, Jaegwon. Supervenience and Mind. Cambridge: Cambridge University Press, 1993, p. 22-32.

LEWIS, David. Extrinsic properties. Philosophical Studies 44, p. 197-200, 1983.

LOMBARD, Lawrence. Relational change and relational changes. Philosophical Studies 34, p. 63-79, 1978. 
MCDANIEL, Kris. Ways of being. In: CHALMERS, D.; MANLEY, D. \& WASSERMAN, R. Metametaphysics: new essays on the foundations of ontology. Oxford: Oxford University Press, 2009, p. 290-319.

MCDONOUGH, Richard. Martin Heidegger's Being and Time. New York: Peter Lang, 2006.

MCMANUS, Denis. Ontological pluralism and the Being and Time project. Journal of the History of Philosophy, 51(4), p. 651-673, 2013.

REIS, Róbson. Aspectos da modalidade. A noção de possibilidade na fenomenologia hermenêutica. Rio de Janeiro: Via Vérita, 2014.

- Historicidade e necessidade existencial em Ser $e$ Tempo de Martin Heidegger. Filosofia Unisinos, 17(1), p. 2-12, 2016.

THOMPSON, Iain. Death and Demise in Being and Time. In: WRATHAL, M. (org.), The Cambridge Companion to Heidegger's Being and Time. New York: Cambridge University Press, 2013, p. 260-290.

WEBERMAN, David. Gadamer, Non-Intentionalism and the Underdeterminedness of Aesthetic Properties. $O$ que nos faz pensar, 18, p. 255-272, 2004.

. A New Defense of Gadamer's Hermeneutics. Philosophy and Phenomenological Research LX (Jan), p. 45$65,2000$.

. Cambridge Changes Revisited: Why Certain Relational Changes are Indispensable. Dialectica, 53, p. 139- 
149, 1999.

. The Nonfixity of the Historical Past. Review of Metaphysics 50 (June), p. 749-768, 1997.

WITHY, Katherine. Situation and Limitation: Making Sense of Heidegger on Thrownness. European Journal of Philosophy, 22(1), p. 61-81, 2011. 